06.1

\title{
Поглощение электромагнитного излучения аморфным углеродом, модифицированным металлами
}

\author{
(C) С.Г. Ястребов ${ }^{1}$, И.Е. Истомин ${ }^{1, \uparrow}$, М. Singh ${ }^{2}$ \\ ${ }^{1}$ Физико-технический институт им. А.Ф. Иофрфе РАН, Санкт-Петербург, Россия \\ ${ }^{2}$ Western University, London, Ontario, Canada \\ E-mail: kesha22ist@gmail.com
}

Поступило в Редакцию 28 августа 2020 г.

В окончательной редакции 28 сентября 2020 г.

Принято к публикации 29 сентября 2020 г.

\begin{abstract}
Представлено теоретическое исследование рассеяния и поглощения электромагнитной волны в диапазоне от гигагерцевого до красного для модели аморфного углерода, модифицированного металлами. На основе структурных исследований этого материала в качестве кандидата выбрана цилиндрическая анизотропная наночастица - нанотрубка, ответственная за его поглощающие и антиотражающие свойства. Разработана модель такой частицы и рассчитаны сечения рассеяния и поглощения электромагнитной волны в рамках теории дискретного дипольного приближения. Модель рассеивающего центра в виде пары нанотрубок позволила объяснить вклад взаимодействия непосредственных соседей в рассеяние и поглощение. Построенная модель объясняет эффект поглощения радиочастотного электромагнитного излучения, наблюдаемый экспериментально в аморфном углероде, модифицированном металлами.
\end{abstract}

Ключевые слова: углеродные нанотрубки, цилиндрические анизотропные наночастицы, радиопоглощающие материалы, радиопоглощающие покрытия, поглощение электромагнитных волн наночастицами.

DOI: 10.21883/PJTF.2021.02.50539.18531

Аморфный углерод, модифицированный металлами, как было обнаружено, обладает антиотражающими свойствами в гигагерцевом диапазоне длин волн [1] и представляет собой набор колончатых структур (цилиндров) [2].

Интерес к материалам, содержащим колончатые структуры, связан также с синтезом нового материала Vantablack (от англ. vertically aligned nanotube arrays (вертикально ориентированные массивы нанотрубок) + black (черный)) - субстанции из углеродных нанотрубок [3], которая получена сравнительно недавно группой в Суррее (Англия) (Surrey Nanosystems) и обладает рядом интересных свойств (см., например, $[3,4]$ ). Массив из вертикально выровненных одностенных углеродных нанотрубок, нанесенных на подложку, обладает почти постоянной и почти единичной поглощающей способностью 0.98-0.99 в широком спектральном диапазоне от ультрафиолетового $(200 \mathrm{~nm})$ до дальнего инфракрасного $(200 \mu \mathrm{m})[4]$.

Поскольку структуру аморфного углерода формируют столбчатые проводящие структуры, в качестве модели рассеивателя электромагнитного излучения возьмем нанотрубку, которая является ближайшим аналогом колончатой структуры.

В свою очередь в качестве модели нанотрубки рассмотрим длинный фрагмент графена, свернутый в трубку. Детали сворачивания опустим. Считаем длину фрагмента достаточной, чтобы исключить эффекты продольного размерного квантования. Верхние концы трубки закрыты полусферическими крышками, напоминающими структуру половины молекулы фуллерена (рис. 1,a).
Диэлектрические свойства трубки различаются для продольной и поперечной составляющих электромагнитного поля. Для каждой точки внутри нанотрубки можно записать локальный диэлектрический симметричный тензор, который в декартовой системе координат примет вид [5]:

$$
\hat{\varepsilon}(\mathbf{r}, \omega)=\left(\begin{array}{ccc}
\frac{x^{2}}{r^{2}} \varepsilon_{\|}(\omega)+\frac{y^{2}}{r^{2}} \varepsilon_{\perp}(\omega) & \frac{x y}{r^{2}}\left(\varepsilon_{\|}(\omega)-\varepsilon_{\perp}(\omega)\right) & 0 \\
\frac{x y}{r^{2}}\left(\varepsilon_{\|}(\omega)-\varepsilon_{\perp}(\omega)\right) & \frac{y^{2}}{r^{2}} \varepsilon_{\|}(\omega)+\frac{x^{2}}{r^{2}} \varepsilon_{\perp}(\omega) & 0 \\
0 & 0 & \varepsilon_{\perp}(\omega)
\end{array}\right) .
$$

Здесь $r-$ радиус углеродной нанотрубки; $\varepsilon_{\|}, \varepsilon_{\perp}-$ диэлектрические функции, соответствующие двум различным направлениям поляризации электрического поля $\mathbf{E}$ : $\mathbf{E} \perp \mathbf{c}, \mathbf{E} \| \mathbf{c}$, где $\mathbf{c}-$ ось симметрии, перпендикулярная базисной плоскости графита.

В задаче моделирования радиус одностенной углеродной нанотрубки принимался равным $0.75 \mathrm{~nm}$, а длина нанотрубки равнялась $10 \mathrm{~nm}$. Комплексный коэффициент преломления определялся как $\tilde{n}=n+i \kappa$. Вещественная $(n)$ и мнимая $(\kappa)$ части комплексного коэффициента преломления для задачи были взяты из работы [6]. Диэлектрические функции $\varepsilon_{\|}(\omega)$ и $\varepsilon_{\perp}(\omega)$ были вычислены по формулам

$$
\begin{gathered}
\varepsilon(\omega)=\varepsilon_{1}(\omega)+i \varepsilon_{2}(\omega), \\
\varepsilon_{1}=n^{2}-\kappa^{2}, \\
\varepsilon_{2}=2 n \kappa,
\end{gathered}
$$

где $\varepsilon_{1}(\omega)$ - вещественная часть комплексной диэлектрической проницаемости, $\varepsilon_{2}(\omega)-$ мнимая часть ком- 

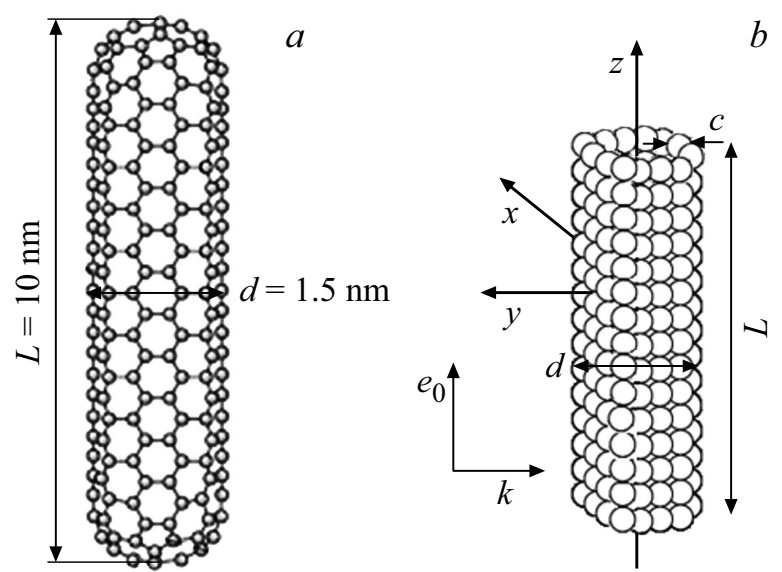

Рис. 1. $a-$ модель колончатой структуры; $b-$ разбиение на диполи методом DDA.

плексной диэлектрической проницаемости, $n$ - вещественная часть комплексного показателя преломления, $\kappa$ - мнимая часть комплексного показателя преломления. Пара нанотрубок позволила нам объяснить вклад взаимодействия непосредственных соседей в рассеяние и поглощение.

Расчет сечений поглощения и рассеяния проводился с помощью метода DDA (discrete dipole approximation) в среде MATLAB [7]. Разбиение на диполи методом DDA схематично показано на рис. $1, b$. В качестве малого объема был взят прямой параллелепипед с ромбом в основании. Высота прямого параллелепипеда была взята равной $0.77 \AA$, сторона ромба - $0.246 \mathrm{~nm}$, один из углов ромба - $120^{\circ}$. Диаметр углеродной нанотрубки был взят равным $1.5 \mathrm{~nm}$, длина углеродной нанотрубки $10 \mathrm{~nm}$. C помощью DDA была рассчитана амплитудная функция, которая зависит от направления рассеяния, поляризации падающей волны и ориентации частицы по отношению к падающей волне. С помощью этой функции можно вычислить сечения рассеяния, экстинкции и поглощения соответственно по формулам [8]:

$$
\begin{gathered}
C_{\text {sca }}=\frac{1}{k^{2}} \int|F(\theta, \phi)|^{2} d \Omega, \\
C_{e x t}=\frac{4 \pi}{k^{2}} \operatorname{Re}(F(0)), \\
C_{a b s}=C_{\text {ext }}-C_{\text {sca }},
\end{gathered}
$$

где интегрирование проводится по всему телесному углу, $d \Omega=\sin \theta d \theta d \phi$ - элемент телесного угла, $F(\theta, \phi)$ - амплитудная функция, $F(0)$ - амплитудная функция для направления вперед, $k$ - волновой вектор.

В результате моделирования оказалось, что в рассматриваемом диапазоне спектра при ориентации электрического вектора электромагнитной волны вдоль оси нанотрубки происходит в основном ее поглощение при минимуме рассеяния. При ориентации электрического вектора поперек трубки как рассеяние, так и поглощение оказываются пренебрежимо малыми по сравнению с параллельной ориентацией. Поэтому мы далее не приводим зависимостей сечений рассеяния и экстинкции для поперечной поляризации.

На рис. 2, а показаны сечения поглощения электромагнитной волны для одиночной нанотрубки и нанотрубки, взаимодействующей со второй, которая расположена параллельно первой и находится от нее на расстоянии $1.5 \mathrm{~nm}$. Из этого рисунка видно, что сечение поглощения электромагнитной волны нанотрубки, взаимодействующей со второй, меньше сечения поглощения одиночной нанотрубки. На рис. 2, $b$ показаны сечения рассеяния электромагнитной волны для нанотрубки, взаимодействующей со второй. Из этого рисунка видно, что сечение рассеяния электромагнитной волны сначала растет, а затем убывает с увеличением расстояния между нанотрубками.

Взаимодействие трубок друг с другом незначительно изменяет сечения экстинкции и рассеяния.
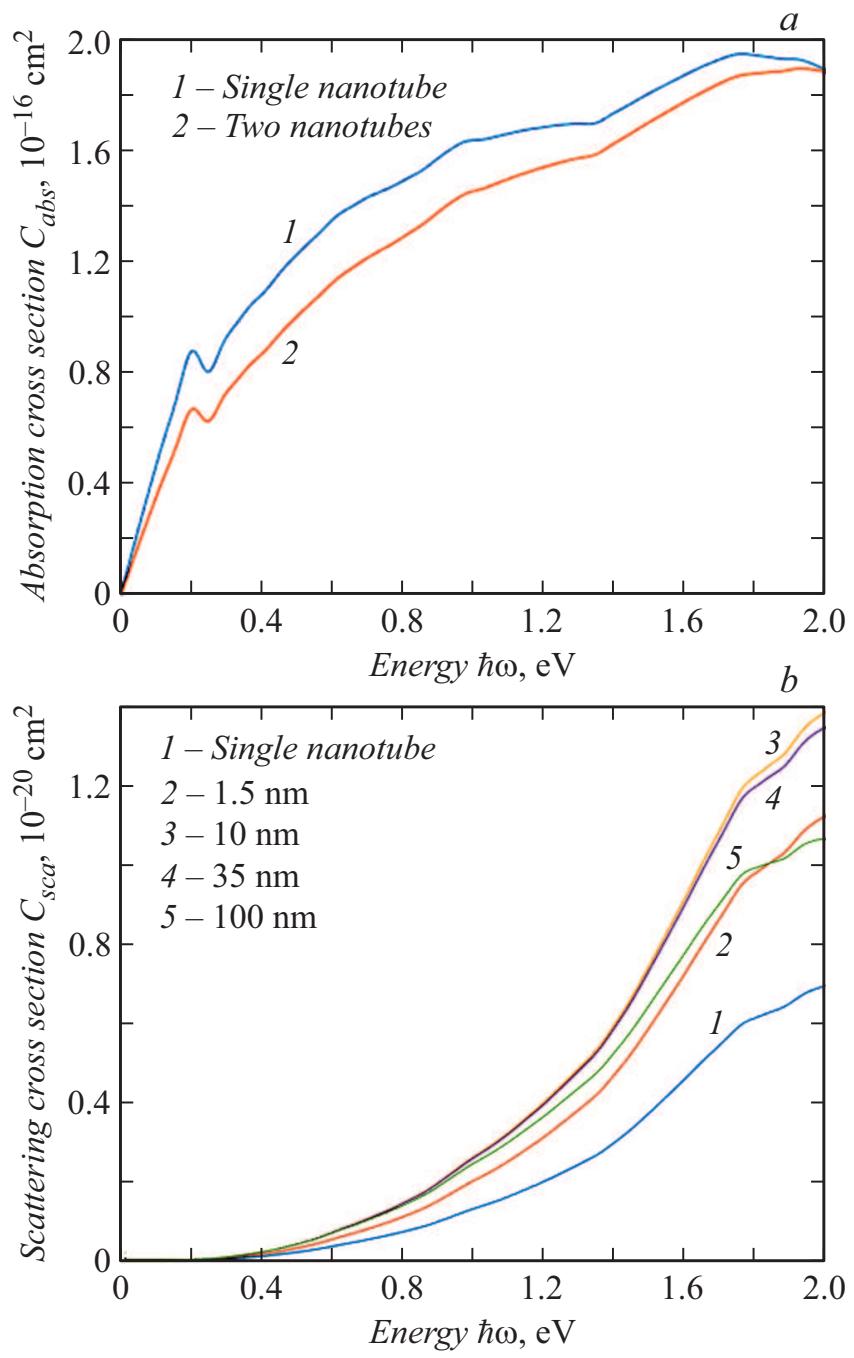

Рис. 2. $a-$ сечения поглощения одиночной нанотрубки и нанотрубки, взаимодействующей со второй, находящейся от нее на расстоянии $1.5 \mathrm{~nm} ; b-$ сечения рассеяния нанотрубки, взаимодействующей со второй. 
Выполненный расчет позволяет объяснить поглощение электромагнитного излучения радиочастотного диапазона спектра композита, содержащего вытянутые проводящие образования в качестве элемента структуры.

Результаты моделирования свидетельствуют о том, что, изменяя длину углеродной нанотрубки, можно варьировать ее сечения поглощения и экстинкции в инфракрасном и радиочастотном диапазонах. Изменяя расстояние между проводящими цилиндрическими наночастицами, можно варьировать их сечения поглощения и экстинкции. Выполненные расчеты могут оказаться полезными при выявлении связи между микро- и наноструктурой известных современных нанокомпозитов и их отражающими свойствами, а также при конструировании ряда новых композиционных материалов.

\section{Финансирование работы}

Один из авторов (M. Singh) благодарит Natural Sciences and Engineering Research Council of Canada (NSERC) за предоставление исследовательского гранта.

\section{Конфликт интересов}

Авторы заявляют, что у них нет конфликта интересов.

\section{Список литературы}

[1] L.V. Lutsev, S.V. Yakovlev, T.K. Zvonareva, A.G. Alexeyev, A.P. Starostin, S.V. Kozyrev, J. Appl. Phys., 97 (10), 104327 (2005). DOI: 10.1063/1.1913797

[2] Т.К. Звонарева, В.И. Иванов-Омский, А.В. Нащекин, Л.В. Шаронова, ФТП, 34 (1), 96 (2000).

[3] E. Theocharous, C.J. Chunnilall, R. Mole, D. Gibbs, N. Fox, N. Shang, G. Howlett, B. Jensen, R. Taylor, J.R. Reveles, O.B. Harris, N. Ahmed, Opt. Express, 22 (6), 7290 (2014).

[4] K. Mizuno, J. Ishii, H. Kishida, Y. Hayamizu, S. Yasuda, D.N. Futaba, M. Yumura, K. Hata, Proc. Natl. Acad. Sci. USA, 106 (15), 6044 (2009).

[5] F.J. Garcia-Vidal, J.M. Pitarke, J.B. Pendry, Phys. Rev. Lett., 78 (22), 42 (1997).

[6] A.B. Djurišić, E.H. Li, J. Appl. Phys., 85 (10), 7404 (1999).

[7] M.A. Yurkin, A.G. Hoekstra, J. Quant. Spectrosc. Radiat. Transf., 106 (1-3), 558 (2007).

[8] Г. ванде Хюлст, Рассеяния света малыми частицами (ИИЛ, М., 1961). 